\title{
Empowering children to make and shape our digital futures - from adults creating technologies to children transforming cultures
}

\author{
Netta Iivari \\ INTERACT Research Unit, University of Oulu, Oulu, Finland
}

Received 1 March 2020

Revised 5 June 2020

15 August 2020

Accepted 18 August 2020

\begin{abstract}
Purpose - Digital technology education of children needs to be reconsidered. The purpose of this paper is to focus on empowering the young generation as regards digital technology. Digital technology education should reap the benefits of recent developments brought in by extensive, ongoing digitalization and prepare the young generation to manage and master in their technology rich future. The recent COVID 19 pandemic has made this particularly relevant and visible in the society. The young generation should adopt a proactive and critical stance toward digital technology and consider how design and technology can be used for making the world a better place.
\end{abstract}

Design/methodology/approach - This commentary reviews literature on the complex concept of empowerment and suggests a model on the aspects to be considered when aiming at empowering the young generation as regards digital technology in the context of digital technology education.

Findings - A model is proposed that comprehensively addresses empowerment of children as regards digital technology both at individual and collective levels and in mainstream sense as a relational and motivational construct as well as in critical sense in terms of collective empowerment, social responsibility and liberation of the oppressed.

Research limitations/implications - Radical renewal in the children's education is needed in the digital age. This model outlines aspects to be considered in such a transformation. The insights should be valuable for research communities addressing the topic of children's education in the digital age in general or the topic of children's digital technology education in particular.

Practical implications - The model should also be of help for practitioners, i.e. teachers and facilitators working in informal learning spaces for developing children's digital education in practice.

Social implications - The commentary addresses significant societal issues. It is actually not only children who should be empowered to engage in making and shaping our digital futures, but people in general. The model provides novel and valuable insights on what aspects to consider in such a significant endeavor.

Originality/value - The model proposed is novel and clearly needed in the research addressing this topic.

Keywords Schools, Empowerment, Education, Children, Digital technology design

Paper type Viewpoint

\section{Introduction}

The extensive and continuous digitalization of our everyday life poses numerous challenges for the society, including education of the young generation. Indeed, digitalization in basic education is currently a hot topic among a number of disciplines and research communities. This commentary focuses particularly on the young generation and their basic education in the digital age. Children of today will for sure be living their adult life full of digital technology. Alarming is that even if today's children have been surrounded by digital

(C) Netta livari. Published by Emerald Publishing Limited. This article is published under the Creative Commons Attribution (CC BY 4.0) licence. Anyone may reproduce, distribute, translate and create derivative works of this article (for both commercial and non-commercial purposes), subject to full attribution to the original publication and authors. The full terms of this licence may be seen at http:// creativecommons.org/licences/by/4.0/legalcode

This study was funded by Academy of Finland (Grant \#324685, Make-a-Difference project).

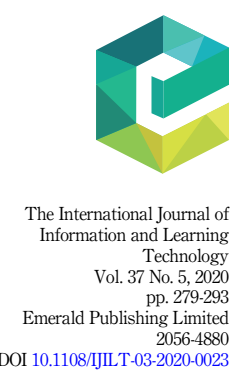


IJILT 37,5

technology from their birth, they have severe limitations in technology comprehension. Schools should prepare the young generation for the needs of the digital future; however, schools struggle in offering children up to date and high quality digital technology or STEM education: schools and teachers may lack, e.g. resources, skills, competencies or interest (e.g. Godhe et al., 2019; Kinnula et al., 2015; OECD, 2018; Smith et al., 2018; Vainionpää et al., 2019). Even if there is an extensive interest to improve digital technology or STEM education of children around the globe, accomplished for instance through integrating programming or digital fabrication into the basic education curricula (e.g. Balanskat and Engelhardt, 2014; Blikstein, 2013; Dindler et al., 2020; Godhe et al., 2019; NCBE, 2016) and even if children's digital technology and STEM education is increasingly offered also in nonformal learning settings such as in computer, programming, robotics or Maker clubs, museums or science centers (e.g. Tisza et al., 2019), many countries and children are staying badly behind these recent developments. One problem is that nonformal learning settings do not comprehensively reach the young generation, but rather reproduce various kinds of digital divides, e.g. around gender or the socioeconomic status of the participants (e.g. OECD, 2018; Tisza et al., 2019).

This commentary concentrates on the digital technology education of children, maintaining that the young generation needs to be empowered as regards digital technology. Such education should adapt to and take advantage of recent developments brought in by extensive and ongoing digitalization and prepare the young generation to manage and master in their technology rich future life. The recent COVID 19 pandemic has made this particularly relevant and visible in the society: in a flash, basic education of the young generation was transformed from a classroom practice to an online mode, requiring significant adjustments from teachers, children and their families. Entire generation of children had to start managing with digital means and tools to take part in their basic education. Parents had to support their children in many respects to make this happen. Teachers had to decide on the suitable means and tools and fit those with the pedagogical practice in meaningful ways. During this trajectory, it became visible that different kinds of digital divides prevail in the society: definitely not all children were in equal position to take advantage of their basic education online (see, e.g. Hilppö et al., 2020; Horowitz, 2020; livari et al., 2020; Larkins, 2020). Along these lines, it is pivotal to provide the young generation with equal opportunities to access, use and gain benefit from digital technology. Even access might be an issue for some children and families as well as ability to use different kinds of digital technologies (see, e.g. Hilppö et al., 2020; Iivari et al., 2020; Larkins, 2020). Furthermore, digital divide is not merely about access or use but about being able to integrate digital technology into meaningful social practices (Livingstone and Helsper, 2007; Mariën and Prodnik, 2014; Warschauer, 2002). In the case of COVID 19, for example, ability to meaningfully integrate digital means and tools into one's learning practices may be limited among some children and their families (e.g. Iivari et al., 2020; Larkins, 2020).

More generally, it is important that the young generation adopts a proactive stance toward digital technology. They should acknowledge that current digital technology has been created by adults for children, while children should be more proactively engaged and consider how technology could and should be, not merely accept how it is. Moreover, they should be prepared to make and shape the trajectories of digital technology in their adult life. Currently, quite a limited group of technology experts have specified the technology we use (see, e.g. Vainionpää et al., 2019), while in the future today's children should bring more diversity into digital technology development, looking at digital technology critically and considering how it could be better and taking action. For this to happen, they need to gain skills and competences to innovate, design, program and build digital technology (Blikstein, 2013; Godhe et al., 2019; Iivari et al., 2018; Heeley and Damodaran, 2009; Mariën and Prodnik, 2014). Hence, the focus is not only on programming or making of digital technology but also in 
creative design and innovation of it (Blikstein et al., 2013; Iivari and Kinnula, 2018; Iversen et al., 2017). The existing research has argued children are the experts in "being kids," and this expertise needs to be available for the development of digital technology aimed at them (e.g. Druin et al., 1997; Ruland et al., 2007). The literature has already shown children are capable of ideating, designing as well as making interesting and valuable (digital) solutions for their own use as well as for the use of others, which should be better acknowledged by adults as well as supported further (see, e.g. Druin et al., 1997; Horelli and Kaaja, 2002; Kratzer and Lettl, 2008; Ruland et al., 2007; Weibert et al., 2015).

The need to empower the young generation as regards digital technology has been already acknowledged by several research communities. Children have for long been considered not only as learners and users of digital technology but as testers, informants and equal design participants to adults (Druin, 2002), while currently there is arousing interest toward even more influential role for children as regards digital technology. The inspiration for this is derived from various sources: from educational philosophies such as critical pedagogy and constructionism (Freire, 2000; Papert, 1993), from Scandinavian participatory design tradition and movements, philosophies and approaches aiming at democratizing of innovations, such as from the open source software and hardware, Do-It-Yourself and Maker movements, end user development and meta design (see, e.g. Björgvinsson et al., 2010; Ehn, 2008; Fischer, 2002; Fischer, 2013; Greenbaum and Kyng, 1991; Simonsen and Robertson, 2013; von Hippel, 2005) and as well as from research on children's empowerment and genuine participation produced within a variety of disciplines (e.g. Chawla and Heft, 2002; Hart, 1992). The literature argues for empowerment of children as regards digital technology and for inviting children to adopt a role of protagonist, in which one is critically reflecting on digital technology and its trajectories as part of one's everyday life as well as taking lead in making and shaping it (Dindler et al., 2020; Iivari et al., 2018; Iivari and Kuutti, 2018; Iversen et al., 2017; Kinnula et al., 2017). The literature maintains that a Maker and designer mindset or identity among children should be nurtured (Chu et al., 2015, 2017; Fischer, 2002; livari and Kinnula, 2018). As for the digital technology education of the children, this implies a radical renewal: we should consider educating and raising future protagonists and activists, who try to make the world a better place through design and technology - i.e. acting as transformers of culture rather than mere passive consumers of digital technology (cf. Fischer, 2013). Along these lines, Fischer et al. (2020) argue that in the digital age learners should be invited to start acting as active contributors, rather than passive consumers and engage in solving contemporary ill-defined problems, acting as designers. Such a change in the mindset and practices of learners definitely needs support and facilitation. Fischer et al. (2020) argue that important is to equip the young generation with skills to alter, design and choose between possible futures, being also aware of and capable to reflect on ethical implications and power laden issues involved. As regards such education, we should also critically reflect on the schools' role in society and appreciate the potential of nonformal learning settings in making this change - offering settings in which the participants want to learn, rather than have to learn (Fischer et al., 2020).

Overall, even if there seems to be consensus on the importance of the topic of empowerment of children to start making and shaping digital technology in the literature, there are also many complexities involved. There are many practical challenges involved (see, e.g. Kinnula et al., 2017), but problematic is also that there is no shared understanding what is meant by the concept: it has been addressed within a multitude of disciplines with a number of meanings associated with it (e.g. Conger and Kanungo, 1988; Hardy and Leiba-O'Sullivan, 1998; Spreitzer, 1995; Thomas and Velthouse, 1990). As regards the topic of children and digital technology, one can find a number of studies mentioning empowerment of children, but very different meanings being attached to it, if defined at all (Iivari and Kuutti, 2018; Kinnula et al., 2017). Only one study can be found that offers a detailed discussion of the
Empowering children to make and shape our digital futures

281 
IJILT 37,5

282 different meanings and forms of empowerment in the literature on children and digital technology (Kinnula et al., 2017); however, also this study can be criticized as lacking certain perspectives of empowerment, for example a motivational one discussed extensively in the literature on worker empowerment within different disciplines (see, e.g. Rajanen and Iivari, 2019). Hence, this commentary builds upon a recent review on the concept of empowerment addressing adults (Rajanen and Iivari, 2019), while refines it to fit the context of empowerment of children as regards digital technology, inspired by the existing literature on the topic (for a review, see Kinnula et al., 2017) and offers a discussion of the meanings that should be associated with the concept of empowerment in the context of children and their digital technology education. In this commentary, digital technology education is considered as taking place both in formal and nonformal settings (cf. Eshach, 2007), with both having particular strengths but also particular weaknesses in supporting empowerment of children.

The commentary is structured as follows. The next section reviews the literature on the concept of empowerment, clarifying different meanings and forms that can be considered in the context of children and their digital technology education. The following section summarizes the findings in a model, aiming at comprehensively capturing significant aspects to be considered in digital technology education, aiming at empowering children to make and shape digital technology. The last section discusses the implications of the model on research and practice, its limitations and interesting paths for future work implied by it.

\section{Different meanings of empowerment}

From the extensive literature on empowerment, one can identify different streams. For example, the literature has distinguished mainstream and critical views on empowerment (see Hardy and Leiba-O'Sullivan, 1998, see also Kinnula et al., 2017; Rajanen and Iivari, 2019) as well as empowerment as a relational and a motivational construct (see Conger and Kanungo, 1988). Conger and Kanungo (1988) discuss the latter distinction: empowerment as a relational construct views it from the perspective of increased, shared or delegated power over something or someone (Conger and Kanungo, 1988, see also Hardy and Leiba-O'Sullivan, 1998) with emphasis on decision-making: either on the mobilization of resources to affect it or on the control of access to it (Hardy and Leiba-O'Sullivan, 1998). Empowerment as a motivational construct, then again, considers it from the viewpoint of self-determination or intrinsic task motivation (Conger and Kanungo, 1988; Thomas and Velthouse, 1990). Within this stream, empowerment is approached rather as enabling than as delegating; it is seen as something internal to an individual rather than something done by others to an individual (Conger and Kanungo, 1988; Hardy and Leiba-O'Sullivan, 1998; Thomas and Velthouse, 1990). Both approaches to empowerment can be associated with the mainstream and critical views to empowerment that will be discussed next.

The mainstream view of empowerment relies heavily on the discipline of psychology and addresses the topic in the context of the workplace and worker empowerment (see, e.g. Conger and Kanungo, 1988; Spreitzer, 1995; Thomas and Velthouse, 1990). Critics argue that empowerment in this literature is being approached as a managerial tool (Hardy and LeibaO'Sullivan, 1998) - indeed this literature views empowerment as valuable, as it increases worker motivation, self-efficacy and decision-making power that are seen to lead to increased effectiveness, productivity and innovation (e.g. Conger and Kanungo, 1988; Spreitzer, 1995; Thomas and Velthouse, 1990), all this indicating strong association between management goals and worker empowerment.

Within this stream, Thomas and Velthouse's (1990) model on empowerment, viewing empowerment as a motivational construct, is a widely cited example. It operationalizes empowerment as increased intrinsic task motivation that "involves positively valued experiences that individuals derive directly from a task" (Thomas and Velthouse, 1990, 
p. 668). Four aspects related to a task are introduced in the model as central: impact, which refers to "to the degree to which behavior is seen as 'making a difference' in terms of accomplishing the purpose of the task, that is, producing intended effects in one's task environment"; competence, which refers to "the degree to which a person can perform task activities skillfully when he or she tries"; meaningfulness, which refers to "the value of the task goal or purpose, judged in relation to the individual's own ideals or standards" and "the individual's intrinsic caring about a given task" and choice, which refers to "whether a person's behavior is perceived as self-determined" (Thomas and Velthouse, 1990, pp. 672673, discussed also, e.g. in Spreitzer, 1995; Deng et al., 2016; Rajanen and Iivari, 2019).

As for empowerment of children as regards digital technology, the mainstream view on empowerment identifies important aspects: it argues for children gaining increased decisionmaking power as regards digital technology as well as posits that children should perceive impact, competence, meaningfulness and choice when they engage in making and shaping of digital technology.

The critical view on empowerment, then again, attacks the mainstream view and proposes alternative understandings on it (see, e.g. Hardy and Leiba-O'Sullivan, 1998; Rajanen and Iivari, 2019). However, one can identify a lot if diversity within this view (see, e.g. Hardy and Leiba-O'Sullivan, 1998). The work may be based on, for example, scholars such as Habermas, Foucault or Freire (see, e.g. Hardy and Leiba-O'Sullivan, 1998; Fulton, 1997). Generally, the critical view on empowerment maintains that there are oppressed groups and conditions in the world and empowerment entails that these oppressed groups critically scrutinize as well as contest the oppressing historical, social and political conditions of the status quo - within this view it is seen that empowerment entails that the marginalized, dominated or oppressed overcome or combat such marginalization, domination or oppression, which requires that they become aware of the oppressing conditions in the first place as well as take action to make a change (see, e.g. Fulton, 1997; Hardy and Leiba-O'Sullivan, 1998; Jennings et al., 2006; Rajanen and Iivari, 2019). Within the critical view on empowerment, collective concerns and social responsibility are also underscored. "In the broadest sense, empowerment refers to individuals, families, organizations, and communities gaining control and mastery, within the social, economic, and political contexts of their lives, in order to improve equity and quality of life" (Jennings et al., 2006, p. 32, see Zimmerman, 1995). Empowerment thus necessitates community engagement as well as a critical examination of the sociopolitical contexts and processes involved (Zimmerman, 1995).

Representing critical, community oriented view to empowerment, Jennings et al. (2006, p. 41) model captures a comprehensive set of aspects;

(1) "A welcoming and safe environment

(2) Meaningful participation and engagement

(3) Equitable power-sharing between youth and adults

(4) Engagement in critical reflection on interpersonal and sociopolitical processes

(5) Participation in sociopolitical processes to effect change; and

(6) Integrated individual- and community-level empowerment"

In this model social responsibility is underscored; empowerment of oneself but also empowerment of others needs to be addressed (Jennings et al., 2006, see also Rajanen and Iivari, 2019)

As for empowerment of children as regards digital technology, one could say that the critical view brings in significant issues to be considered that have been neglected within the mainstream view. The critical view emphasizes that children should consider not only
Empowering children to make and shape our digital futures

283 
IJILT

37,5

themselves when engaging with digital technology but they should always consider a broader community and social responsibility vis a vis a larger collective. Empowerment in this case should entail critically reflecting on the oppressing conditions of the status quo as well as action taking, involving in our case design and technology among other means, for liberating the oppressed and for improving their well-being and quality of life.

\section{4}

\section{Empowerment of children to make and shape our digital futures}

Based on the literature on worker empowerment (most notably Thomas and Velthouse, 1990; Jennings et al., 2006), Rajanen and Iivari (2019) propose a comprehensive model on empowerment to be used in the context of open source usability. In this commentary, this model is taken as a basis while it is developed, based on the literature on empowerment of children as regards digital technology (Kinnula et al., 2017, see also Iversen et al., 2017; Iivari and Kinnula, 2016; livari and Kinnula, 2018) as well as more general literature addressing children's empowerment (e.g. Chawla and Heft, 2002; Hart, 1992; Jennings et al., 2006), to fit the context of children and their digital technology education. The model (see Table 1) outlines what needs to be considered when we aim at empowering the young generation to start engaging in making and shaping our digital futures. The first four aspects in the model address empowerment in the mainstream sense, aiming at motivational empowerment of children in the context of digital technology making and shaping, while the last five aspects address empowerment in connection to digital technology making and shaping in the critical sense, addressing also collective aspects of empowerment. These aspects are concretized with examples inspired by the COVID 19 pandemic as well as with additional literature touching upon children's empowerment - this literature offers practical examples as well as potential challenges.

The model addresses empowerment very comprehensively: both at individual and collective levels and in mainstream sense as a relational and motivational construct (Conger and Kanungo, 1988; Thomas and Velthouse, 1990; Deng et al., 2016) as well as in critical sense in terms of a collective empowerment, social responsibility and liberation of the oppressed (Fulton, 1997; Hardy and Leiba-O'Sullivan, 1998; Jennings et al., 2006). Children's education should start addressing all these aspects of empowerment: in the case of digital technology education, it is pivotal to consider children's empowerment in the motivational sense to ensure their participation, but equally crucial is to show to children that engagement with digital technology enables them to address empowerment in a much broader sense: it is not only their own needs and use of digital technology that should be considered, but much more broadly communities' needs, well-being and quality in life. Children should feel social responsibility for those less privileged in the society and consider how design and technology could make a difference in their lives and well-being. Children should critically reflect on the problematic conditions of the status quo and take action to change it. They should also work in a participatory manner with the target group: they should invite the less privileged or marginalized groups or communities to participate in making a change through design and technology. Addressing these aspects of empowerment in the education of children enables raising future protagonists, activists and agents of change, who look at the world critically, take social responsibility seriously and take action with design and technology for making the world a better place. All this implies a radical change toward children starting to act as transformers of culture.

The model should be useful for people involved in children's formal as well as nonformal digital technology education. The nonformal setting in many respects aligns better with the empowerment ideals: within it, children want to learn, rather than have to learn. However, formal setting is equally significant as within compulsory basic education one comprehensively reaches entire age groups and prevents children from missing out due to 


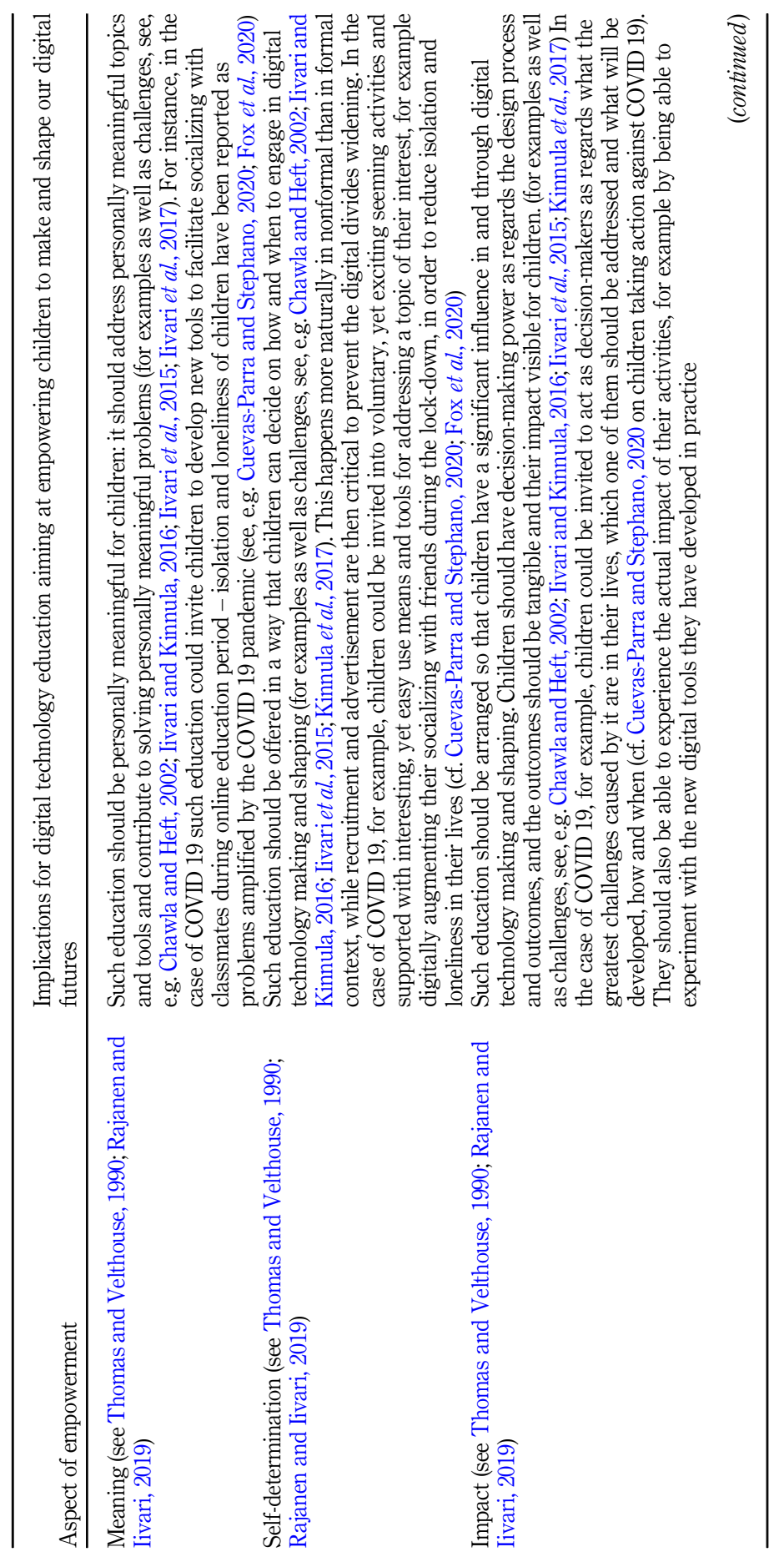

Empowering children to make and shape our digital futures

285

Table 1.

Aspects to consider in digital technology education aiming at empowering the young generation to make and shape our digital 
IJILT
37,5

286

Table 1.

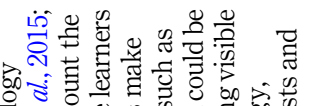

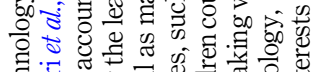

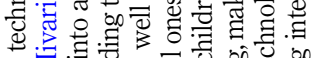
焉它 o

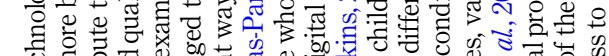

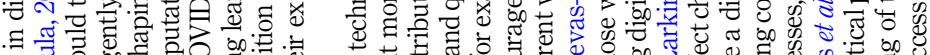

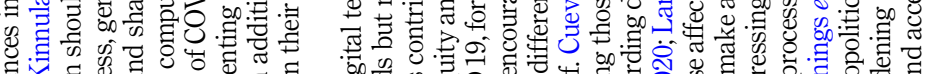

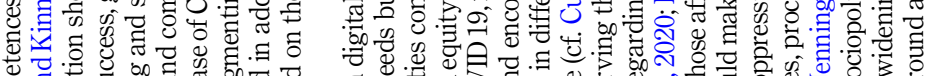

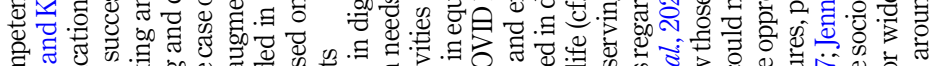

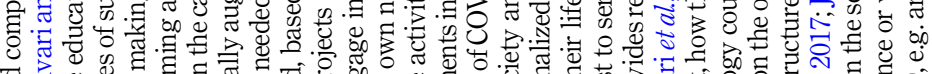

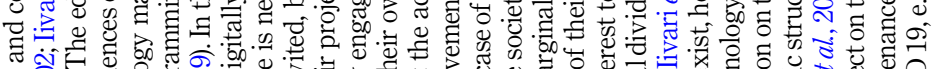

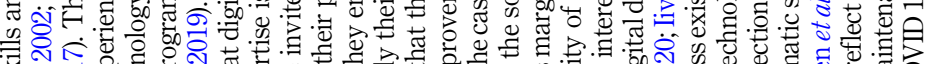

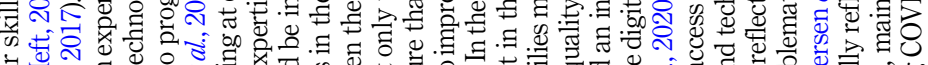

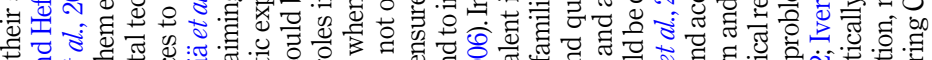

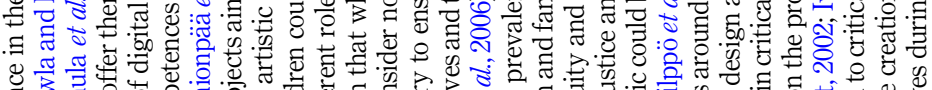

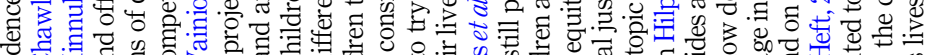

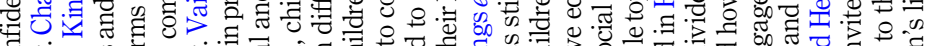

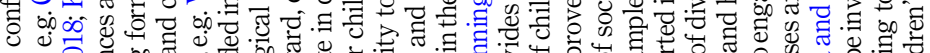

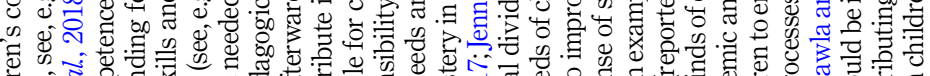

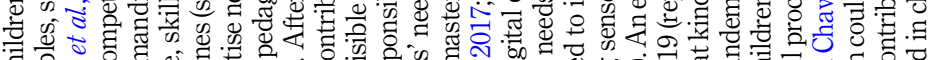

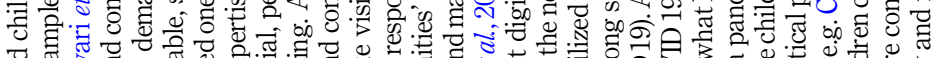

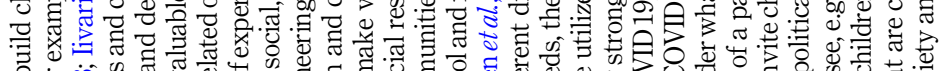

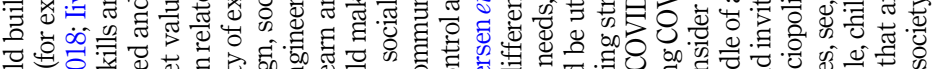

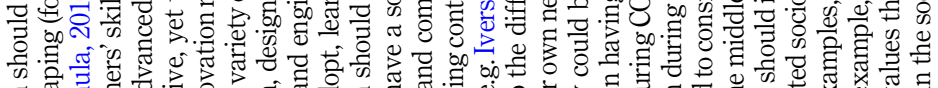

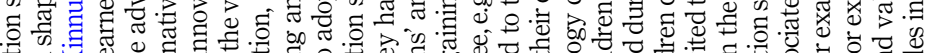

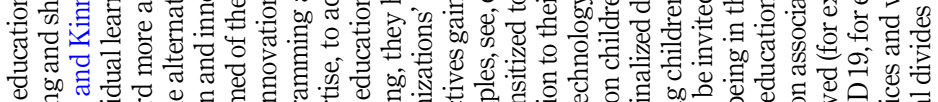

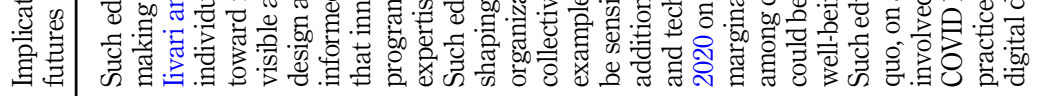

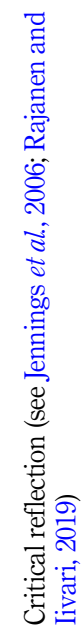




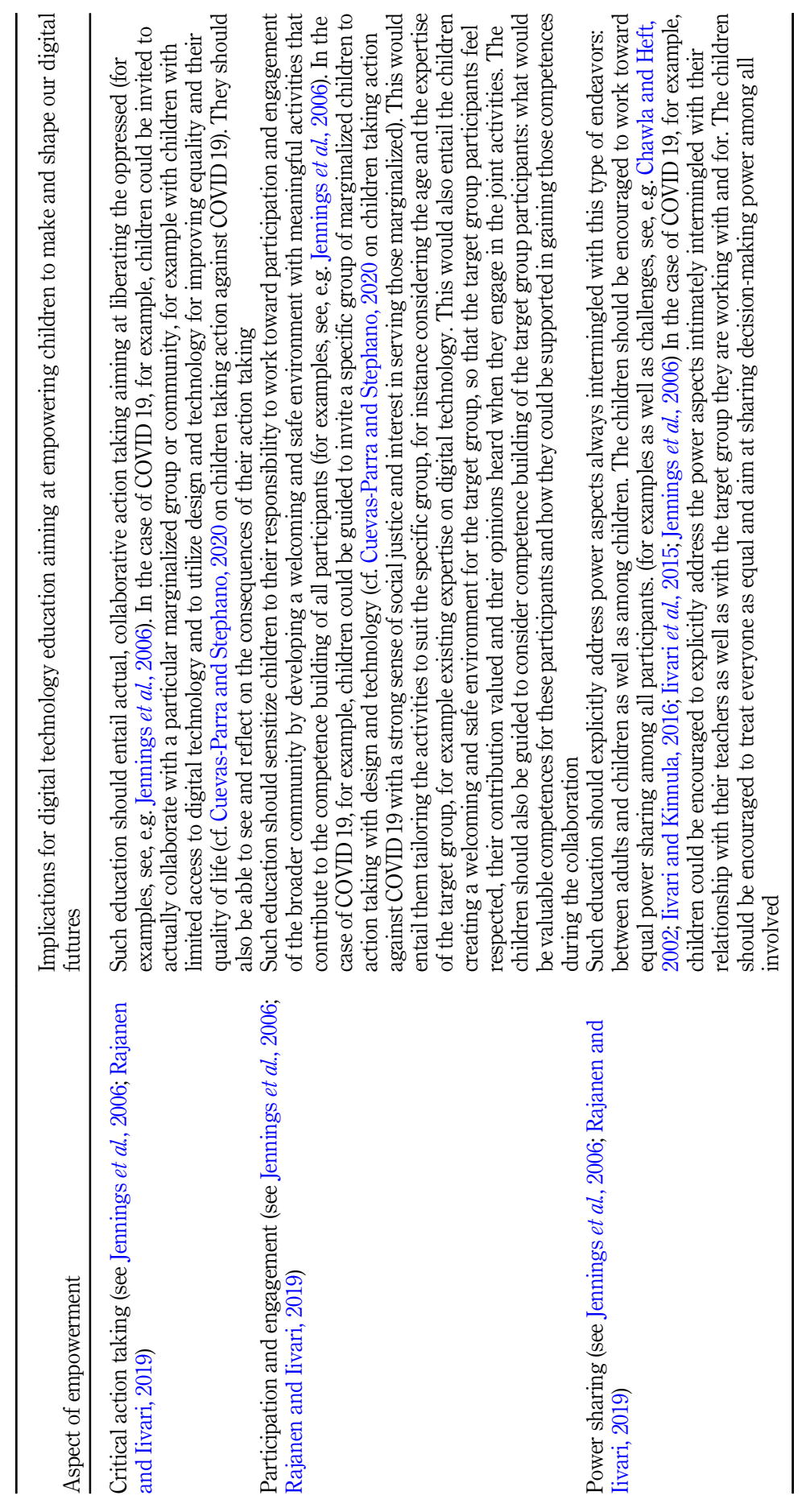

Empowering children to make and shape our digital futures

287

Table 1. 
IJILT 37,5

288 prejudice or lack of pre-interest or information (cf. Iivari and Kinnula, 2016). With the model, educators in both contexts can make conscious choices on which aspects of empowerment they wish to address with children and to which extent. They can take the very important motivational aspects of empowerment into account: they should design the activities and topics so that children experience them as meaningful and interesting, that children have as much decision-making power as possible regarding their participation as well as regarding the activities and topics, that they get opportunities to see and experience the impact of their work and that they can develop self-efficacy building on their own interests and expertise when engaging in the activities. Moreover, with the model the educators can consider how they could address the highly significant critical aspects of empowerment with children. They can reflect on how to make visible for children that design and technology offer opportunities beyond the individual: design and technology can be used for making the world a better place and for improving equality and quality of life of those marginalized, oppressed or dominated. The critical aspects emphasize that among children social responsibility should be underscored, critical reflection on the current status quo aroused and action taking with design and technology initiated. Overall, with this model, educators can start practically planning their projects with children, considering if and how these different aspects of empowerment can and should be included and the extent it is possible to include them in practice.

There are many limitations and challenges to be considered. For example, in formal education the activities may not be voluntary for children to attend and full power sharing among teachers and pupils may be unrealistic. The activities need to fit with the curriculum, and the teachers need to exercise their authority and duty of care to decide upon many issues in children's digital technology education without consulting the children. There may be occasions in which the teacher decides to allow children to engage in decisionmaking to an unusual extent, but in many cases these aspects may limit in practice what kind of empowerment can be aimed at. However, this should not prevent from aiming at addressing other aspects of empowerment. Moreover, nonformal settings are not without limitations and challenges either. In both contexts there likely are situations in which selfdetermination and full decision-making power cannot and should not be allowed for children alone, but many issues remain adults' responsibility or are determined within collaboration with peers or by contextual affordances and restrictions. The educators may also deem certain topics so important to address with children that the perceived meaningfulness or self-determination among children are not top priorities. There are also many problems in the world related to solving of which the children's contribution can only be marginal. However, this should not be used as an excuse of not trying at all. The same goes for the challenging tasks of arousing social responsibility among children, inviting children to reflect on the problematic conditions of the status quo, inviting them on taking action to make the world a better place and supporting the participation and engagement of other participants. These definitely are not easy tasks to accomplish by children. One challenge is also that the educators need to feel confident and competent when addressing these topics with children. In addition, they need to be able to tailor their approach to address these topics in an age appropriate manner. Depending on the age of the children, the educators may need to simplify these tasks a lot. However, valuable projects can be ideated even with kindergarten children, addressing for example the digital divides, bullying or gender equality. Finally, one may even criticize that by inviting children into this type of adult led and specified way to question and combat the status quo, we are taking away one of their last resources for revolt, critique and change. Definitely this is not the aim. Instead, the hope is that through sensitizing children to this type of critical approach toward design and technology enables them to start acting as future protagonists, activists and agents of change. 


\section{Conclusions}

This commentary concentrated on digital technology education of children, maintaining that the young generation needs to be empowered as regards digital technology. Such education should reap the benefits of recent developments brought in by extensive and on-going digitalization and prepare the young generation to manage and master in their technology rich future life. The recent COVID 19 pandemic has made this particularly relevant and visible in the society. This commentary pointed out that it is important that the young generation adopts a proactive stance toward digital technology. Children should start looking at digital technology critically and consider how it could be made better. However, empowerment is a complex concept with a variety of meanings attached to it. This commentary, inspired by recent reviews on the concept, offers a refined model of what empowerment may entail in the context of children's digital technology education. The model addresses empowerment comprehensively: both at individual and collective levels and in mainstream sense as a relational and motivational construct as well as in critical sense in terms of a collective empowerment, social responsibility and liberation of the oppressed.

Overall, radical renewal in the children's education is needed in the digital age. This commentary addresses some aspects to be considered in such a transformation. The insights discussed in this commentary should be valuable for research communities addressing the topic of children's education in the digital age in general as well as the topic of children's digital technology education in particular. The model presented in this commentary should be of help for researchers as well as for practitioners, i.e. teachers and facilitators working in formal and nonformal learning settings, for developing the education in practice. This model aims at providing food for thought and a tool for reflection. This model can be considered as meta-design; it aims at enabling those previously marginalized and excluded to take part in digital technology development as well as proposes a design for design after design, rather than merely advocating design before use (see, e.g. Björgvinaaon et al., 2010; Ehn, 2008; Fischer, 2002; Fischer, 2013). Such a meta design actually considers not only children to be in need for empowerment to engage in making and shaping our digital futures but people in general. Currently, our digital futures are specified by quite a limited group of technology experts (see, e.g. Vainionpää et al., 2019), while this model provides novel and valuable insights on what aspects to consider when empowering people as regards digital technology, particularly addressing children, but applicable with adults as well.

It is acknowledged that there are many challenges involved in this kind of transformation of education. There are many fundamental tensions between the model and the formal schooling culture, some of which have been touched upon by Godhe et al. (2019) in the context of making in education. For sure the model does not directly fit with formal schooling, but instead a lot of support for teachers and schools and modification of the approach to empowerment will be needed (see also Godhe et al., 2019; Fischer et al., 2020). Nonformal learning settings may encounter relatively similar problems, even if they tend to be more flexible and participation tends to be voluntary. In both settings, however, in terms of selfdirection, impact, meaningfulness, power sharing and critical reflection and action taking, there are several social, cultural, political as well as technical consideration and hurdles to be overcome.

The model is based on insights gained during over ten years work on the topic of empowerment of children in and through digital technology design and making, while the model has not been empirically evaluated as such. This is future work to be done. However, related work on genuine or effective participation of children has empirically examined and shown the relevance of many of the aspects in the model: the model by Chawla and Heft (2002) on effective participation of children builds on empirical research carried out by an entire research community. Their conditions of genuine participation of children have been empirically explored in several studies in the context of children and digital technology (e.g.
Empowering children to make and shape our digital futures

289 
IJILT 37,5
Iivari and Kinnula, 2016; Iivari et al., 2015; Sharma et al., 2020). One study has already empirically examined relational aspects of empowerment as regards children and digital technology as well as pointed out the value of critical aspects of empowerment in this context (Kinnula et al., 2017). Hence, even if lacking empirical evidence in this particular commentary, the model has strong grounding in empirical work with children.

This commentary ends up arguing that children of today should be empowered in and through their digital technology education to switch from mere users of digital technologies created by adults to makers and shapers of such technologies and, along these lines, to transformers of culture. Hence, the commentary extends the focus from creation of digital tools - by adults or children - to the transformation of our digital futures, into which children should be invited as active agents early on.

\section{References}

Balanskat, A. and Engelhardt, K. (2014), Computing Our Future: Computer Programming and CodingPriorities, School Curricula and Initiatives Across Europe, European Schoolnet, Brussels.

Björgvinsson, E., Ehn, P. and Hillgren, P.A. (2010), "Participatory design and democratizing innovation", Proceedings of the 11th Biennial Participatory Design Conference, pp. 41-50.

Blikstein, P. (2013), "Digital fabrication and 'making' in education: the democratization of invention", in Walter-Herrmann, J. and Büching, C. (Eds), Fab Labs: Of Machines, Makers and Inventors, Transcript Publishers, Bielefeld.

Chawla, L. and Heft, H. (2002), “Children's competence and the ecology of communities: a functional approach to the evaluation of participation", Journal of Environmental Psychology, Vol. 22 Nos 1-2, pp. 201-216.

Chu, S.L., Quek, F., Bhangaonkar, S., Ging, A.B. and Sridharamurthy, K. (2015), "Making the maker: a means-to-an-ends approach to nurturing the maker mindset in elementary-aged children", International Journal of Child-Computer Interaction, Vol. 5, pp. 11-19.

Chu, S.L., Schlegel, R., Quek, F., Christy, A. and Chen, K. (2017), "I make, therefore I Am': the effects of curriculum-aligned making on children's self-identity", Proceedings of the 2017 CHI Conference on Human Factors in Computing Systems (CHI'17), Association for Computing Machinery, New York, NY, pp. 109-120.

Conger, J.A. and Kanungo, R.N. (1988), "The empowerment process: integrating theory and practice”, Academy of Management Review, Vol. 13 No. 3, pp. 471-482.

Cuevas-Parra, P. and Stephano, M. (2020), "Children's voices in the time of COVID-19: continued child activism in the face of personal challenges", World Vision International 2020, available at: https://www.wvi.org/sites/default/files/2020-04/WV-Children \%E2\%80\%99s \%20voices $\% 20$ in $\% 20$ the $\% 20$ time $\% 20$ of $\% 20$ COVID-19\%20Final.pdf.

Deng, X., Joshi, K.D. and Galliers, R.D. (2016), "The duality of empowerment and marginalization in microtask crowdsourcing: giving voice to the less powerful through value sensitive design", MIS Quarterly, Vol. 40 No. 2, pp. 279-302.

Dindler, C., Smith, R.C. and Iversen, O.S. (2020), "Computational empowerment: participatory design in education”, CoDesign, Vol. 16 No. 1, pp. 66-80.

Druin, A. (2002), "The role of children in the design of new technology", Behaviour and Information Technology, Vol. 21 No. 1, pp. 1-25.

Druin, A., Stewart, J., Proft, D., Bederson, B. and Hollan, J. (1997), "KidPad: a design collaboration between children, technologists, and educators", Proceedings of the ACM SIGCHI Conference on Human factors in Computing Systems, pp. 463-470.

Ehn, P. (2008), "Participation in design things", Proceedings Participatory Design Conference 2008, ACM.

Eshach, H. (2007), "Bridging in-school and out-of-school learning: formal, non-formal, and informal education”, Journal of Science Education and Technology, Vol. 16 No. 2, pp. 171-190. 
Fischer, G. (2002), "Beyond 'couch potatoes': from consumers to designers and active contributors", First Monday, Vol. 7 No. 12, available at: https:/journals.uic.edu/ojs/index.php/fm/article/ download/1010/931.

Fischer, G. (2013), "End-user development: from creating technologies to transforming cultures", International Symposium on End User Development, Springer, Berlin, Heidelberg, pp. 217-222.

Fischer, G., Lundin, J. and Lindberg, J.O.J. (2020), "Rethinking and reinventing learning, education and collaboration in the digital age-from creating technologies to transforming cultures", International Journal of Information and Learning Technology, Vol. ahead-of-print No. aheadof-print, doi: 10.1108/IJILT-04-2020-0051.

Fox, E., Parsons, S., Todorovic, A., Songco, A. and Lim, M. (2020), "Achieving resilience during COVID-19", Oxford ARC Study, Summary report 1, Oxford University, Oxford.

Freire, P. (2000), Pedagogy of the Oppressed, Vol. 35, Continuum, New York, NY, 30th anniv.

Fulton, Y. (1997), "Nurses' views on empowerment: a critical social theory perspective", Journal of Advanced Nursing, Vol. 26 No. 3, pp. 529-536.

Godhe, A.L., Lilja, P. and Selwyn, N. (2019), "Making sense of making: critical issues in the integration of maker education into schools", Technology, Pedagogy and Education, Vol. 28 No. 3, pp. 317-328.

Greenbaum, J. and Kyng, M. (1991), Design at Work: Cooperative Design of Computer Systems, L. Erlbaum Associates, Hillsdale.

Hardy, C. and Leiba-O'Sullivan, S. (1998), "The power behind empowerment: implications for research and practice", Human Relations, Vol. 51 No. 4, pp. 451-483.

Hart, R.A. (1992), “Children's participation: from tokenism to citizenship”, Papers inness92/6, Innocenti Essay.

Heeley, M. and Damodaran, L. (2009), "Digital inclusion: a review of international policy and practice", available at: http://projects.computing.dundee.ac.uk/iden/outcomes/LeelaMelanieInternationalPolicyReview.doc Date (accessed 8 December 2017).

Hilppö, J., Rainio, A., Rajala, A. and Lipponen, L. (2020), Children and the COVID-19 Lockdown: From Child Perspectives to Children's Perspectives, Cultural Praxis, available at: http://culturalpraxis. net/wordpress1/2020/04/26/children-and-the-covid-19-lockdown-from-child-perspectives-tochildrens-perspectives/.

Horelli, L. and Kaaja, M. (2002), "Opportunities and constraints of 'internet-assisted urban planning' with young people", Journal of Environmental Psychology, Vol. 22 Nos 1-2, pp. 191-200.

Horowitz, J. (2020), Lower-income Parents Most Concerned about Their Children Falling behind amid COVID-19 School Closures, Pew Research Center, available at: https://www.pewresearch.org/ fact-tank/2020/04/15/lower-income-parents-most-concerned-about-their-children-falling-behindamid-covid-19-school-closures/.

Iivari, N. and Kinnula, M. (2016), "Inclusive or inflexible: a critical analysis of the school context in supporting children's genuine participation", Proceedings of the 9th Nordic Conference on Human-Computer Interaction, pp. 1-10.

Iivari, N. and Kinnula, M. (2018), "Empowering children through design and making: towards protagonist role adoption", Proceedings of the 15th Participatory Design Conference: Full Papers, Vol. 1, pp. 1-12.

Iivari, N. and Kuutti, K. (2018), "Critical design in interaction design and children: impossible, inappropriate or critical imperative?", Proceedings of the 17th ACM Conference on Interaction Design and Children, pp. 456-464.

Iivari, N., Kinnula, M. and Kuure, L. (2015), "With best intentions”, Information Technology and People, Vol. 28 No. 2, pp. 246-280.
Empowering children to make and shape our digital futures 
IJILT 37,5

Iivari, N., Kinnula, M., Molin-Juustila, T. and Kuure, L. (2017), "Multiple voices in the maker movement-a nexus analytic literature review on children, education and making", Proceeding ECIS2017.

Iivari, N., Kinnula, M., Molin-Juustila, T. and Kuure, L. (2018), "Exclusions in social inclusion projects: struggles in involving children in digital technology development", Information Systems Journal, Vol. 2018, pp. 1-29.

Iivari, N., Sharma, S. and Ventä-Olkkonen, L. (2020), "Digital transformation of everyday life-how COVID-19 pandemic transformed the basic education of the young generation and why information management research should care?", International Journal of Information Management, Vol. 55, 102183.

Iversen, O.S., Smith, R.C. and Dindler, C. (2017), "Child as protagonist: expanding the role of children in participatory design", Proceedings of the 2017 Conference on Interaction Design and Children, pp. 27-37.

Jennings, L.B., DeborahParra-Medina, M., DeanneHilfinger-Messias, K. and McLoughlin, K. (2006), "Toward a critical social theory of youth empowerment", Journal of Community Practice, Vol. 14 Nos 1-2, pp. 31-55.

Kinnula, M., Laari-Salmela, S. and Iivari, N. (2015), "Mundane or magical? Discourses on technology adoption in Finnish schools", Proceedings ECIS2015.

Kinnula, M., Iivari, N., Molin-Juustila, T., Keskitalo, E., Leinonen, T., Mansikkamäki, E. and Similä, M. (2017), "Cooperation, combat, or competence building-what do we mean when we are 'empowering children' in and through digital technology design?", Proceedings of International Conference on Information Systems, AIS.

Kratzer, J. and Lettl, C. (2008), "A social network perspective of lead users and creativity: an empirical study among children”, Creativity and Innovation Management, Vol. 17 No. 1, pp. 26-36.

Larkins, C. (2020), Building on Rainbows: Supporting Children's Participation in Shaping Responses to COVID-19, available at: https://clok.uclan.ac.uk/33087/.

Livingstone, S. and Helsper, E. (2007), "Gradations in digital inclusion: children, young people and the digital divide”, New Media and Society, Vol. 9 No. 4, pp. 671-696.

Mariën, I. and Prodnik, A.J. (2014), "Digital inclusion and user (dis) empowerment: a critical perspective", Info, Vol. 16 No. 6, pp. 35-47.

National Core Curriculum for Basic Education (NCCBE) (2016), "Perusopetuksen opetussuunnitelman perusteet; Määräykset ja ohjeet 2014:96 [national core curriculum for basic education; regulations and guidelines]", Opetushallitus: Next Print Oy, 4th ed., available at: http://www.oph. fi/download/163777_perusopetuksen_opetussuunnitelman_perusteet_2014.pdf.

Organisation for Economic Co-operation and Development (OECD) (2018), Bridging the Digital Gender Divide: Include, Upskill, Innovate, OECD, Paris.

Papert, S. (1993), “The children's machine”, Technology Review-Manchester NH, Vol. 96, p. 28.

Rajanen, M. and Iivari, N. (2019), "Empowered or disempowered? An analysis of usability practitioners' interventions in open source projects", in Leroux, J. (Ed.), Psychological Perspectives on Empowerment, Nova Science Publishers, Hauppauge, pp. 1-45.

Ruland, C.M., Slaughter, L., Starren, J., Vatne, T.M. and Moe, E.Y. (2007), "Children's contributions to designing a communication tool for children with cancer", Studies in Health Technology and Informatics, Vol. 129 No. Pt 2, pp. 977-982.

Simonsen, J. and Robertson, T. (Eds) (2013), Routledge International Handbook of Participatory Design, Routledge, New York, NY.

Sharma, S., Achary, K., Kinnula, M., Iivari, N. and Varkey, B. (2020), "Gathering garbage or going green? shifting social perspectives to empower individuals with special needs", in Proceedings of the Interaction Design and Children Conference, pp. 311-322. 
Smith, R.C., Iversen, O.S. and Veerasawmy, R. (2018), "Impediments to digital fabrication in education: a study of teachers' role in digital fabrication”, Information and Technology Literacy: Concepts, Methodologies, Tools, and Applications, IGI Global, Hershey, pp. 301-319.

Spreitzer, G.M. (1995), "Psychological empowerment in the workplace: dimensions, measurement, and validation”, Academy of Management Journal, Vol. 38 No. 5, pp. 1442-1465.

Thomas, K.W. and Velthouse, B.A. (1990), "Cognitive elements of empowerment: an 'interpretive' model of intrinsic task motivation”, Academy of Management Review, Vol. 15 No. 4, pp. 666-681.

Tisza, G., Papavlasopoulou, S., Christidou, D., Voulgari, I., Iivari, N., Giannakos, M.N., Kinnula, M. and Markopoulos, P. (2019), "The role of age and gender on implementing informal and non-formal science learning activities for children", in Proceedings of the FabLearn Europe 2019 Conference, pp. 1-9.

Vainionpää, F., Kinnula, M., Iivari, N. and Molin-Juustila, T. (2019), "Gendering and segregation in girls' perceptions of IT as a career choice-A nexus analytic inquiry”, Proceedings ISD2019.

von Hippel, E. (2005), Democratizing Innovation, MIT Press, Cambridge, MA.

Warschauer, M. (2002), "Reconceptualizing the digital divide”, First Monday, Vol. 7 No. 7.

Weibert, A., Aal, K., von Rekowski, T. and Wulf, V. (2015), "Hey, can we make that, please?: on craft as a means of cross-cultural community-building”, The Journal of Community Informatics, Vol. 11 No. 2, pp. 1-9.

Zimmerman, M.A. (1995), "Psychological empowerment: issues and illustrations", American Journal of Community Psychology, Vol. 23 No. 5, pp. 581-599.

\section{Corresponding author}

Netta Iivari can be contacted at: netta.iivari@oulu.fi
Empowering children to make and shape our digital futures

For instructions on how to order reprints of this article, please visit our website:

www.emeraldgrouppublishing.com/licensing/reprints.htm

Or contact us for further details: permissions@emeraldinsight.com 